\title{
Active Learning and Flipped Classroom, Hand in Hand Approach to Improve Students Learning in Human Anatomy and Physiology
}

\author{
Maria Entezari ${ }^{1} \&$ Mohammad Javdan ${ }^{2}$ \\ ${ }^{1}$ Department of Natural Scinces, LaGuardia Community College, City University of New York, USA \\ ${ }^{2}$ Department of Biological Sciences and Geology, Queensborough Community College, City University of New \\ York, USA
}

Correspondence: Maria Entezari, Department of Natural Scinces, LaGuardia Community College, City University of New York, USA Tel: 1-718-482-6079. E-mail: tentezarizaher@lagcc.cuny.edu

Received: September 28, 2016

Accepted: October 21, 2016

Online Published: October 24, 2016

doi:10.5430/ijhe.v5n4p222

URL: http://dx.doi.org/10.5430/ijhe.v5n4p222

\begin{abstract}
Because Human Anatomy and Physiology (A\&P), a gateway course for allied health majors, has high dropout rates nationally, it is challenging to find a successful pedagogical intervention. Reports on the effect of integration of flipped classrooms and whether it improves learning are contradictory for different disciplines. Thus many educators are reluctant to explore the value of flipped classrooms. Therefore, in the present study we compare incorporating flipped classroom and minimal class discussion (control group) with flipped classroom and active learning activities (experimental group) in A\&P and their impacts on both students' exam performance and their satisfaction with the course. Assessments consisted of a survey of students' attitudes and a comparison of exam performance in experimental and control groups. Exam performance among the students in flipped-classroom and active learning activities improved significantly relative to the control group [Mean \pm SD: $(76.93 \pm 18.33$ vs $67.8 \pm 18.81), p<0.001$. Student attitude, in which students rated the efficiency of pedagogical learning on a five-point Likert scale, was positive: the majority of students strongly preferred active-learning activities that were incorporated in the flipped-classroom. Students indicated that these activities helped them learn better and to connect the materials to the goals of their future careers $(73.88 \%$ and $79.77 \%$ respectively). Therefore, we conclude that flipped classroom coupled with active learning strategies can improve students' performance and attitude in the introductory A\&P course.
\end{abstract}

Keywords: Student-centered, Flipped classroom, Active-learning, Motivation, Performance, Anatomy and Physiology, Undergraduate

\section{Introduction}

\subsection{The Problem}

Human Anatomy and Physiology I (A\&P) is a gateway course into healthcare careers in all two and four-year colleges in U.S. This fundamental course builds the foundations for the other higher level courses in any healthcare majors such as Nursing, Physical Therapy, Occupational Therapy, Radiology Technician, Paramedics, and Nutrition. Human A\&P is offered in the first two semesters in most of the community colleges. It is very important for students to succeed and acquire skills and confidence to that they can advance in their health programs, pass national licensing examinations, and be well-prepared for their future careers. Unfortunately, in our setting (LaGuardia Community College, New York City) we see 30-40\% drop out and failure rates in this course, similar to national trends (Benford \& Gess-Newsome, 2015). This course is therefore a barrier for students who want to pursue a career in healthcare fields. Because they fail, many students have to retake this course several times or drop out from college.

Students withdraw from courses and subsequently from pursuing degrees at community colleges for several reasons, including conflicts with work schedules, personal reasons, parking issues, family obligations, financial difficulties, boredom with classroom activities and teaching styles, and low motivation (Zhai \& Monzon, 2001). We cannot eliminate all the factors that cause students to withdraw from their courses. However, educators may be able to influence some conditions that relate to student retention, especially fear of failure and lack of motivation. 
Student success in Human A\&P correlates with students' better preparation and degree completion (Harris, Hanuum \& Gupta, 2004). In most community colleges students do not arrive at the course with the required academic skills or prior scientific knowledge to succeed in gateway courses such as Human A\&P (Gultice, Witham, \& Kallmeyer, 2015). Therefore, there is an immediate need to provide students with different support services and implement innovative pedagogical approaches in gateway courses.

One promising teaching strategy that improves student performance and attitude in several disciplines is to implement the flipped classroom (Missildine, Fountain, Summers, \& Gosselin, 2013).

\subsection{Background}

In the flipped classroom, course materials such as recorded lectures, tutorial videos, animations, notes, and podcasts are provided outside of the class (Estes, Ingram, \& Liu, 2014). This approach gives more flexibility to instructors to devote the class time to focus on concept engagement through active learning activities, collaborative work, and discussion sessions (Peisachovich, Susan, Phillips, \& Messinger, 2016). This methodology places students' learning needs at the center; they have the opportunity to discuss their ideas, ask questions, and clarify their misconceptions. This strategy contrasts with traditional lecture courses in which students sit back passively in an attempt to absorb the information transmitted by their instructors (Bergmann \& Sams, 2012). In STEM disciplines, using flipped classroom improves students' learning in spite of the challenges that students face for the adjustment to this approach (Ziegelmeier \& Topaz, 2015). Incorporating flipped classroom with active learning activities had a significant impact on increasing grades and problem solving skills of nursing students (Peisachovich, Susan, Phillips, \& Messinger, 2016). Since students have individual learning styles, implementing varied learning activities can have a positive influence on students' motivation and involvement (Haak, HilleRisLambers, Pitre, \& Freeman, 2011).

The aforementioned studies argue in favor of flipped classroom and active learning strategies, but similar success for rates of learning has not been seen in introductory college-level biology courses. Some studies showed the mixed learning outcomes as a result of implementing flipped classroom (Stone,2012; Mason, Shuman \& Cook, 2103) and several studies reported no significant difference in student learning or metacognitive gains between the traditional and flipped sections (Choi, 2013; Daves, Dean, \& Ball, 2013). Zhao and Ho have reported even the reverse effect of flipped classroom on students' scores in the midterm exam (Zhao \& Ho, 2014). They have also reported 53\% of students felt the course is more appealing when they heard about flipping approach. These disappointing results could be attributed to the breadth of the student population or the instructors' inexperience (Andrews, Leonard, Colagrove, \& Kalinowski, 2011).

The flipped classroom is now a growing pedagogical strategy embraced by many universities and colleges (McDonald \& Smith, 2013). However, the educators who teach the science courses often do not recognize that flipping classrooms means more than offering asynchronous video resources or podcasts to students (Johnson et al., 2014) and the computer interaction alone is not sufficient for measuring the effectiveness of the flipped approach (Bishop \& Verleger, 2013). Designing the structure of the flipped classroom should focus on improving the student's problem solving, analyzing and evaluating information skills which promotes the overall learning environment inside the classroom (Bergmann \& Sams, 2012). Faculty also need to consider under which condition the flipped classroom is the most effective strategy. Will flipped classrooms improve the learning process of underprepared students in science courses? The effectiveness of flipped classroom and active learning is not universal among different courses and different populations of students (Weltman \& Whiteside, 2010). It has been shown that designing structured in-class activities is equally important as well- prepared videos for effectiveness of the flipped classroom (Zhao \& Ho, 2014). There is a general need to further investigate the efficacy of implementing flipped classroom for different courses and populations of students especially in community colleges.

\subsection{Objective for the Current Study}

The purpose of current study is to examine the effect of different instructional design to improve the success of students as measured by exam performance; to deepen conceptual understanding; and to increase student satisfaction in the Human Anatomy and Physiology course. We used two different teaching designs: Electronically recorded lecture as a supplement to traditional lecture with limited discussion in classroom, and electronically recorded lecture with interactive activities. The hypothesis was that use of flipped classroom combined with incorporation of active learning strategies can improve students' performance and their satisfaction, resulting in higher rates of successful completion. We achieved a 9-point increase in grades and a substantial improvement in student attitude and confidence. 


\section{Method}

\subsection{Subjects}

This study was conducted at LaGuardia Community College (LaGCC) of the City University of New York (CUNY), which is located in Queens, New York. All participants ( $\mathrm{N}=66 ; 76 \%$ female and $24 \%$ male) were enrolled in two sections of Human Anatomy and Physiology I (A\&P I) during the Fall and Spring semesters. Overall, there was no statistically significant difference in terms of students' sex and age between the control and experimental groups. The students' demographic was 31\% Hispanic, 26\% African American, 23\% White, 12\% Indian and 8\% Asian. Students came from diverse backgrounds and low-income households. This four-credit course enrolls primarily allied health majors who are required to take the course as part of the requirements to enter the programs of study in nursing, physical therapy, occupational therapy, radiological technology, and veterinary technology. All students were concurrently enrolled in a laboratory course that met once a week for three hours. The lab component of the course was not changed. The lecture class met three hours a week for the duration of twelve weeks. This study was conducted in the four lecture sessions of this course including: Homeostasis, basic chemistry, the skeletal system, and the muscular system.

\subsection{Experimental Design and Procedure}

The research methodology used a quasi-experimental design with two conditions. The control condition was a flipped classroom by providing electronically video lectures and course materials as an adjunct to traditional pedagogical (lecture-based) approach with minimal discussion. The intervention condition was using the flipped classroom by providing electronically video lectures and course materials along with implementing of active learning strategies. All of the required materials for the lecture (including outlines, notes, narrated PowerPoint Slides, and animations) were posted on Blackboard one week before each class, for both control and treated groups. Both control and treated groups were taught by the same, experienced instructor. This research study protocol was approved by the LaGCC Institutional Review Board (IRB Approval number 446331-1). All students who agreed to participate in this study signed the consent forms. They were informed that both filling out the questionnaire and participating in the study was voluntary; opting out would not affect their grades.

\subsubsection{Intervention}

The following active learning activities were considered and designed in a way to be suitable for all types of learning styles in order to increase the active participation of students in class (Zha \& Ho,2014).

One-minute paper: At the end of each class, students were asked to write what was the most important thing that they learned in the session, as well as what they still needed to be clarified (Stowe, 2010). All of these notes were collected and read by the instructor after class and explanations for the muddiest points were posted on Blackboard at the same day of class.

Group work and discussion: During each face to face class the students were also given between two to three group based activities. Students were asked to divide in groups of four to work on the given problems as a team. Meanwhile the instructor circulated around the room listening to students' discussions, answering questions, and giving constructive comments whenever students encountered difficulties. After five or ten minutes these questions were posed to the entire class and one or two groups would present their answers (Table1, Appendix 1).

Partial Outline: After giving a ten-minute mini-lecture, students were asked to work in pairs to respond to the prompts that directly correlated to the presented lecture (Table 2, Appendix1).

A personal response card: At each session students were introduced into at least four "clicker questions" for each topic (Table 3, Appendix1). These prompts were presented as multiple choice questions on a PowerPoint slide (Bojinova \& Oigara, 2011). Students had been provided with different colored index cards marked with the letters A through D. In order to respond to the clicker questions students raised their hands while holding the appropriately colored response sheet.

\subsection{Data Collection}

In order to measure the effectiveness of active learning strategies on students' performance, the scores of three exams for the covered topics were compared between the treatment group $(\mathrm{N}=32)$ and control group $(\mathrm{N}=34)$. These three exams were comprised of multiple choice questions. Questions on these exams were categorized according to three hierarchical levels of understanding that ranged from knowledge (Easy), to comprehension and application (Medium), to analysis and synthesis (Difficult) based on Bloom's taxonomy and classification of questions in the test banks of related textbook. The exams were the same for both groups. The amount of content-material covered and 
the order of the lectures were the same for both groups. The same syllabus and same time frame for giving the exams were used in both groups.

Students' attitudes towards the course and flipped classroom with active learning strategies were tested by administering a questionnaire in the treated group that used the Likert-scale (of 1 to 5,1 being strongly disagree and 5 being strongly agree).

\subsection{Statistical Analysis}

Data was compiled using Microsoft Excel 2010. All test scores had values out of 100. A student's test was used to compare the mean for students' grades on each of three exams and among all the exams in treatment and control groups. Students' performance on three hierarchical levels of comprehension was tested by using one-way ANOVA to compare the mean of correct answers in each category among the control and treatment groups. A post-hoc test was performed to determine which means were statistically different from the others. The mean \pm SE (Standard Error) for the students' performance on the exams is shown in the graphs.

The results of the attitude survey are expressed as a percentage of the total number of students who responded to the specific questions on the survey.

\section{Results}

\subsection{Students' Performance}

To determine if active learning strategies have any effect on students' performance, the scores of three exams were compared between the treatment and control groups. To analysis of the data that compares the means for students' performance on three exams; two-sample student t-test was performed, through the F-test the homogeneity of variances was also confirmed.

Students' performance was significantly better on exams one and two, but no significant difference was observed between the treatment and the control groups in exam three.

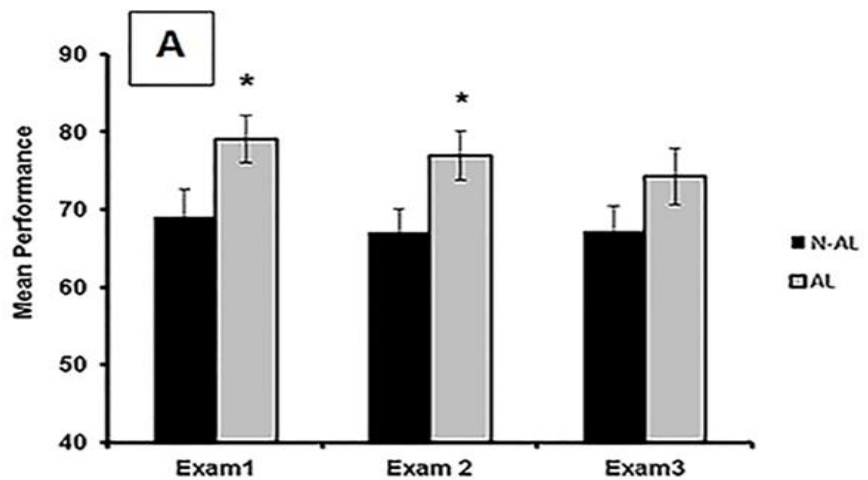

Figure 1A. Mean of Students' Performance for Three Exams

Bar graphs illustrating average grades in each of three exams that administered to the students who were exposed to the active learning strategies in classroom (Active Learning=AL $n=32$ ) vs students who exposed to just the lecture format instruction in classroom (Non-Active Learning=N-AL $n=34$ ). The mean grade for exams one, two, and three in the treatment group vs the control group were [Mean \pm SE; $(79.13 \pm 3.05$ vs $69.06 \pm 3.6 \mathrm{p}<0.05 ; 77 \pm 3.17$ vs $67.06 \pm 3.05 \mathrm{p}<0.05 ; 74.25 \pm 3.63$ vs $67.27 \pm 3.22 \mathrm{p}=0.15$ )] respectively. Data presented as mean \pm Standard Error (SE); $* P<0.05$ significant difference in point scores between the control and experimental groups. (Figure1A). 


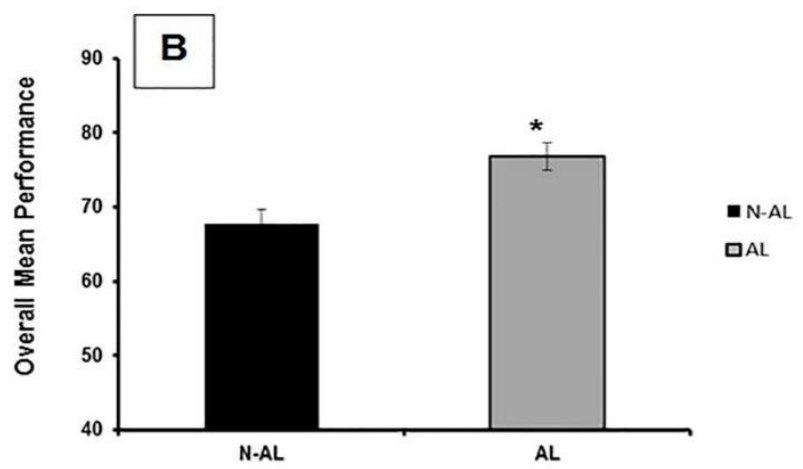

Figure 1B. Mean of Students' Overall Performance

Comparison of pooled grade averages $\pm \mathrm{SE}$ on all three exams that administered to the students who were exposed to the active learning strategies in classroom (Active Learning=AL $n=32$ ) vs students who exposed to just the lecture format instruction in classroom (Non-Active Learning=N-AL $n=34$ ). Students' performance was significantly better in the treatment group for all combining data of the three exams [Mean \pm SE; $76.8 \pm 1.89$ in the treatment group vs $67.8 \pm 1.88$ in the control group, $\mathrm{p}<0.001]$. Data presented as mean \pm Standard Error (SE); * $P<0.05$ significant difference in point scores between the control and experimental groups (Figure 1B).

The mean of given correct answers to the questions on the three exams were ranked as hierarchical levels of understanding as follows: knowledge (Easy), comprehension and application (Medium), analysis and synthesis (Difficult), the data was analyzed by one-way ANOVA.

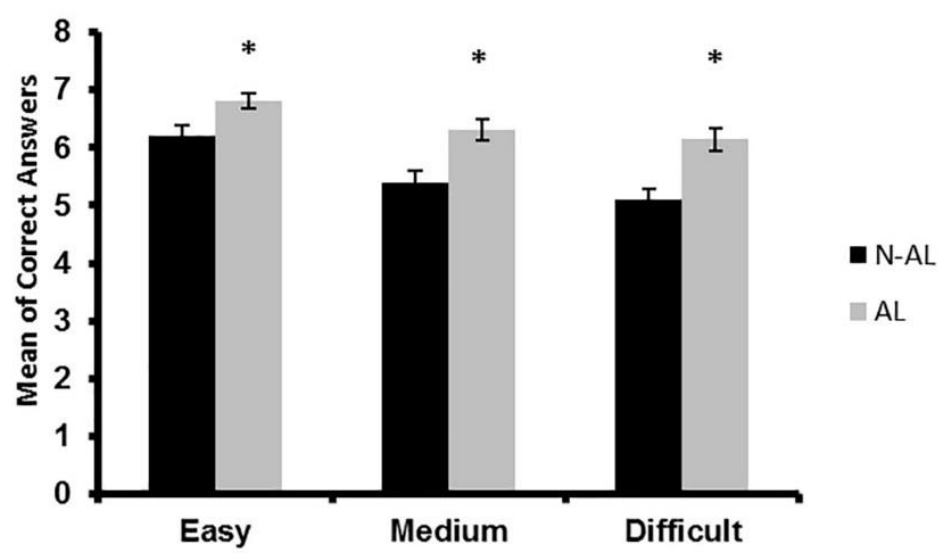

Figure 2. Mean of Given of Correct Answers in Three Exams

The mean of given correct answers for easy, medium, and hard levels in the treatment group vs the control group were [Mean $\pm \mathrm{SE} ;(6.79 \pm 1.3$ vs $6.19 \pm 0.18 p<0.05 ; 6.28 \pm 0.18$ vs $5.38 \pm 0.19 p<0.001 ; 6.14 \pm 0.19$ vs $5.09 \pm 0.2$ $p<0.001$ )] respectively. Data presented as mean \pm Standard Error (SE) on each level of difficulty; * $p<0.05$ significant difference in the percentage of correct answers to different levels of understanding between the control and experimental groups (Figure 2). The pooled data from all three exams have shown significant improvement on the given correct answers on all of three levels in the treatment group where interactive activities incorporated in classroom as opposed to the control group, where introducing course materials was lecture-based with minimal discussion.

\subsection{Students' Attitudes and Retention}

Following completion of all activities in the designated sessions, a brief survey was administered to assess students' satisfaction towards the completion of course and the impact of these activities on their learning. The surveys were filled out anonymously. They administered and analyzed by another instructor from other institution. 
Table 1. Student Survey Responses

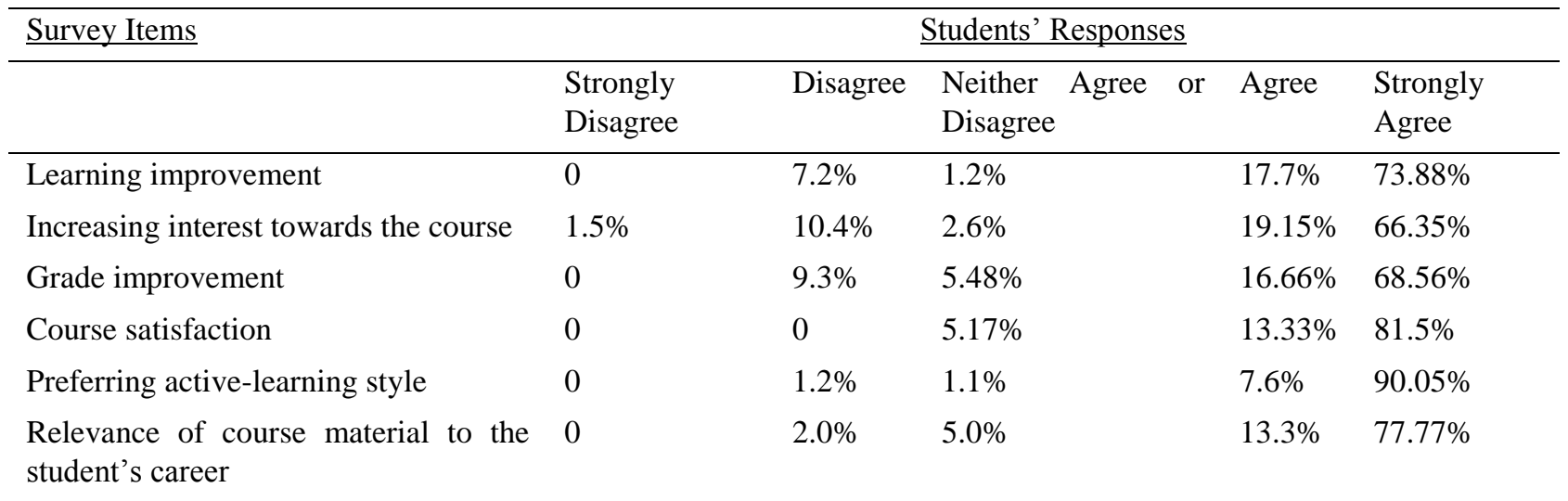

The survey results revealed that $65 \%$ to $95 \%$ of students in the treatment group agreed or strongly agreed on the effectiveness of this approach on their learning and improving their interests towards the course and their scores (Table 1).

As a result of the students' course satisfaction, the rate of students' retention was higher in the treatment group compare to the control group [the percentage of students who completed the course $85 \%$ in the treatment group vs $73 \%$ in the control group].

\section{Discussion}

In traditional pedagogy, a substantial amount of material can be covered in lecture; however, students are often overwhelmed by the content. They struggle to make connections among the facts and to build upon their previous knowledge. In a traditional classroom, students don't have the opportunity to discuss their ideas and misconceptions and there is little interaction between students and their peers and instructors. It is believed that these deficits are the main reason for attrition in science courses and, later, for dropping out of school (Handelsman et al., 2004). It was shown that implementing of either flipped-classroom or active-learning strategies can improve students' performance and attitude (Johnson, Johnson, \& Smith, 1998; Berrett, 2012). Active learning strategies increase students' interaction with their peers and instructor, encourage students' new knowledge to previous knowledge, and provide opportunities for students to reflect on their learning process (Yager, 1991). In contrast, some studies have shown that active learning strategies have no impact on students' achievement at all (Huang \& Carroll, 1997). These discrepancies might be because of differences in the course contents, population of students, the differences in the course structure, or implementing the strategies which are not suitable for a particular course. Therefore, in order to show the effectiveness of implementing flipped classroom and/or active-learning strategies on students' performance, it is important to study the different courses with different population of students and also examine the best way of implementing this approach. The present study shows that incorporating active learning activities and flipping classroom must be together in the content-intensive courses such as Fundamentals of Human Biology (A\& P) to give students the opportunity to be introduced to the course contents out of the classroom, be engaged with their peers, and reflect on their own thinking process in the classroom. Implementing these two elements together helps students to correct their misconceptions and understand the course materials through higher cognitive work which enables students to recall these materials much easier in future (Bransford, Brown, \& Cocking, 2000). This approach also improves students' attitudes towards the course as well as their performance on exams since students are able to understand their growing knowledge by getting an immediate feedback from their peers and instructor.

\subsection{Students' Performance and Helpfulness of Active-learning Components}

Consistent with studies that have shown the benefits of active learning strategies (Walker, Cotner, Baepler, \& Decker, 2008), the data, as shown in Figure 1 A \& B indicate improvement of students' grades as a result of incorporating of active-learning methods in the flipped classroom. Furthermore, the significant improvement of average answered questions at higher levels of understanding (levels two and three, application-analysis $p<0.001$ ) was observed in the treatment group as shown in Figure2. Together, these results indicate that implementing the active-learning strategies in this course improved academic performance and increased students' critical thinking and problem solving skills. These activities helped students identify strategies for enhancing their own learning. This metacognitive awareness is believed to be one of the crucial factors for students' success (Bransford, Brown, \& Cocking, 2000), since it prepares them for more advance courses and independent learning (Armbruster, Patel, Johnson, \& Weiss, 2009). 
Four different strategies in the lecture class were designed and incorporated to improve the students' learning. Using class discussion and working on problems in groups were both very interactive, as the students debated different solutions and approaches to problems. This activity worked especially well for shy students who might be reluctant to ask their questions in class. They felt more comfortable to ask their questions or give their comments while their instructor was circulating in the class. This method also has the benefit of providing immediate feedback about students' understanding and/or misconceptions. This study is consistent with the other studies, which show implementing the active learning activities enhances the depth of student's learning since it gives an immediate gauge of students' understanding on a particular topic (Crouch \& Mazur E, 2001). Students can see the expectation of their instructor in terms of the format and depth of the questions that will appear on their actual exams. This approach also promotes the peer instruction in the class, which is important for the process of student's learning (Smith et al., 2009).

Based on collected responds to survey questions most students found this strategy useful, since it enabled them to make "a whole story" out of the various elements they learned in the class. Similarly, this strategy helped students summarize what they learned and note the points that confused them.

\subsection{Students' Attitude}

Many students in both science and non-science majors believe that science courses are boring and even irrelevant to their daily lives (Rigden \& Tobias, 1991). Some have had bad experiences in science courses and come to class with negative attitudes. Most students are apprehensive about the prospect of performing poorly in a science course (Hemenway, Straits, Wilke, \& Hufnagel, 2001). In this study the incorporation of active-learning strategies gave students the opportunity to discuss their thoughts in a risk free environment. Here interaction between students and the instructor mitigated anxieties about contributing to the class discussion and commenting on the work of peers. As shown in Table 1, 66.35\% students reported increased interest in the course content and a desire to learn more. Previous studies show that increased interest improves learning and can lead to better performance in a course (Svinicki, 2004).

Table 1 also shows that $81.5 \%$ of the students reported being "strongly satisfied" with the course. $73.88 \%$ "strongly believed" that active-learning strategies helped them to learn better, and $68.56 \%$ "strongly believed" it helped them earn a better grade. Incorporating active-learning activities during lectures helps students to become more familiar with the content, connect together various elements of the course, and subsequently to come closer to their career goals. $79.77 \%$ of students indicated that they "strongly believed" that the course materials were relevant to their future career. This result confirmed the positive effect of active-learning strategies on students' motivation and attitude.

Another benefit of these activities was enabling and improving the social interaction among students. Some realized that study groups outside of the classroom helped them understand the course materials better. For instance, a group of students attended the instructor's office hours together in a regular base. Those students who interacted inside and outside of classroom reported more positive attitudes and received better grades than those who appeared to resist the group work.

\section{Conclusions and Future Directions}

This study shows the positive effects of incorporating flipped- classroom and active learning together on students' performance and attitudes in Fundamentals of Human Biology I (A\&P I) course. The survey responses suggest that students like active learning. These strategies benefit instructors as well, increasing their enthusiasm and keeping them more engaged with their students.

This study provides preliminary data and presents a model for incorporating active-learning strategies in a content-intensive course. It shows the importance of revising traditional pedagogies in order to increase both the effectiveness of teaching and students' motivation. With regard to the present study and those previous, it can be argued that learning objectives in science courses should be reconsidered and possibly reconceived. Developing activities that focus on active and collaborative learning is crucial. Flipping of Science courses solely by providing students with course materials in advance and prior to coming to the classroom is not enough and this strategy must be incorporated with different types of classroom activities that are suitable for all types of learning styles. These activities should be designed to show the relevance of the course material to the students' career goals. They should also work to increase students' communication skills. This process is time consuming and requires extensive collaboration between faculty and academic administrators. Through this cooperation, educators can find the best ways to implement these strategies such that students get the maximum benefit. 


\section{Acknowledgments}

This work was supported by Center of Teaching and Learning at LaGuardia Community College, CUNY. The author sincerely thanks the given thoughtful feedback of Michele Piso, Roslyn Orgel, Louise Fluk, and Patricia Sokolski for writing this paper.

\section{References}

Andrews, T.M., Leonard, M.J., Colagrove, C.A., \& Kalinowski, S.T. (2011). Active Learning Not Associated with Student Learning in a Random Sample of College Biology Courses. CBE Life Sci Educ. 10, $394-405$. http://dx.doi.org/10.1187/cbe.11-07-0061

Armbruster, P., Patel, M., Johnson, E., \& Weiss., M. (2009). Active Learning and Student-centered Pedagogy Improve Student Attitudes and Performance in Introductory Biology. CBE Life Sci Educ. 8 , 203-213. http://dx.doi.org/10.1187/cbe.09-03-0025

Benford, R., \& Gess-Newsome, J. (2015) Factors Affecting Student Academic Success in Gateway Courses at Northern Arizona University (online). http://www2.nau.edu/ facdev-p/TR/Factors.pdf.

Bergmann, J. \& Sams, A. (2012). Flip Your Classroom: Reach Every Student in Every Class Every Day. Washington, DC: International Society for Technology in Education.

Berrett, D. (2012). How Flipping the Classroom Can Improve the Traditional Lecture. The Chronicle of Higher Education, February 19. Retrieved from http://chronicle.com/article/How-Flipping-the-Classroom/130857/

Bishop, J.L. \& Verlager, M.A. (2013). The Flipped Classroom: A Survey of the Research. 120th ASEE Annual Conference \&

$$
\text { \& Exposition. }
$$
http://www.studiesuccesho.nl/wpcontent/uploads/2014/04/flipped-classroom-artikel.pdf.

Bojinova, E., \& Oigara, J. (2011). Teaching and Learning with Clickers: Are Clickers Good for Students? Interdisciplinary Journal of E-Learning and Learning Objects, 7(1), 169-184.

Bransford, J. D., Brown, A. L., \& Cocking, R. R. (2000). How People Learn: Brain, Mind, Experience, and School: Expanded Edition. Washington, D. C.

Choi, EM. (2013). Applying Inverted Classroom to Software Engineering Education. International Journal of e-Education, eBusiness, e-Management and e-Learning, Apr; 3(2), 121-125.

Crouch, C. H., \& Mazur, E. (2001). Peer instruction: ten years experience and results. Am. J. Phys, 69, $970-977$. http://dx.doi.org/10.1119/1.1374249

Davies, R. S., Dean, D. L., \& Ball, N. (2013). Flipping the classroom and instructional technology integration in a college-level information systems spreadsheet course. Educational Technology Research and Development, 61(4), 563-580. http://dx.doi.org/10.1007/s11423-013-9305-6

Estes. M. D., Ingram, R., \& Liu, J. C. (2014). A review of flipped classroom research, practice, and technologies. International HETL Review, Volume 4, Article https://www.hetl.org/feature-articles/a-review-of-flipped-classroom-research-practice-and-technologies

Gultice, A., Witham, A., \& Kallmeyer, R. (2015). Are your students ready for anatomy and physiology? Developing tools to identify students at risk for failure. Advances in Physiology Education, 39, 108-115. http://dx.doi.org/10.1152/advan.00112.2014

Haak, D. C., HilleRisLambers, J., Pitre, E., \& Freeman, S. (2011). Increased Structure and Active Learning Reduce the Achievement Gap in Introductory Biology. Science, 332(6034), 1213-1216. http://dx.doi.org/10.1126/science.1204820.

Handelsman, J., Ebert-May, D., Beichner, R., Bruns, P., Chang, A., DeHaan, R., Gentile, J., Lauffer, S., Stewart, J., Tilghman, S.M., \& Wood, W.B. (2004). Scientific teaching. Science, 304(5670), 521-522. http://dx.doi.org/10.1126/science.1096022.

Harris, D. E., Hanuum, L., \& Gupta, S. (2004), Contributing factors to student success in anatomy \& physiology: lower outside workload \& better preparation, Am. Biol. Teach. 66,166-175. http://dx.doi.org/10.2307/4451650

Hemenway, MK., Straits, WJ., Wilke, RR., \& Hufnagel, B. (2001). Educational Research in an Introductory Astronomy Course. Innov Higher Educ., 26, 178-269. 
Huang, AH., \& Carroll, RG. (1997). Incorporating active learning into a traditional curriculum. Am J Physiol Adv Physiol Educ., 273, S14-S23.

Johnson, DW., Johnson, R., \& Smith, K. (1998). Active Learning: Cooperation in the College Classroom. Edina, MN: Interaction Book.

Johnson, L., Becker, SA., Estrada, V., \& Freeman, A. (2014). Horizon Report. Higher Education Edition. Austin, Texas: The New Media Consortium.

Mason, G., Shuman, T., \& Cook, K. (2013). Comparing the Effectiveness of an Inverted Classroom to a Traditional Classroom in and Upper Division Engineering Course accepted to IEEE Transactions on Education. http://dx.doi.org/10.1109/TE.2013.2249066

McDonald, K., \& Smith, CM. (2013). The Flipped Classroom for Professional Development. Part I. Benefits and Strategies. The Journal of Continuing Education in Nursing, 44(10),437-438. PMid:24098988 http://dx.doi.org/10.3928/00220124-20130925-19.

Missildine, K., Fountain, R., Summers, L., \& Gosselin, K. (2013). Flipping the classroom to improve student performance and satisfaction. Journal of Nursing Education, 52(10), 597-599. http://dx.doi.org/10.3928/01484834-20130919-03).

Peisachovich, E.H., Murtha1, S., Phillips, A., \& Messinger, G. (2016). Flipping the Classroom: A Pedagogical Approach to Applying Clinical Judgment by Engaging, Interacting, and Collaborating with Nursing Students. International Journal of Higher Education, 5(4),114-121. http://dx.doi.org/10.5430/ijhe.v5n4p114.

Rigden, JS., \& Tobias, S. (1991). Point of View. Too often, college-level science is dull as well as difficult. Chronicle Higher Educ. A52.

Smith, M. K., Wood, W. B., Adams, W. K., Wieman, C., Knight, J. L., Guild, N., \& Su, T. T. (2009). Why peer discussion improves student performance on in-class concept questions. Science, 323,122-124. http://dx.doi.org/10.1126/science.1165919.

Stone, B. B. (2012). Flip your classroom to increase active learning and student engagement. Paper presented at the 28th Annual Conference on Distance Teaching and Learning, Madison, WI. http://www.uwex.edu/disted/conference/Resource_library/proceedings/56511_2012.pdf

Stowe,,K.(2010). A Quick Argument for Active Learning: The Effectiveness of One-Minute Papers. Journal for Economic Educators, 10(1), 33-39.

Sviniki, M.D. (2004). Learning and Motivation in Postsecondary Classroom. Bolton, MA. Anker, Pub Co.

Walker, J. D., Cotner, S. H., Baepler, P. M., \& Decker, M. D. (2008). A delicate balance: integrating active learning into a large lecture course. CBE Life Sci. Educ.7, 361-367. http://dx.doi.org/10.1187/cbe.08-02-0004.

Weltman, D., \& Whiteside, M. (2010). Comparing the Effectiveness of Traditional and Active Learning Methods in Business Statistics: Convergence to the Mean. Journal of Statistics Education. 18(1),1-13.

Yager, RE. (1991). The constructivist learning model: towards real reform in science education. Sci Teacher, 58, 52-57.

Zhai, L., \& Monzon, R. (2001). Community college student retention: Student characteristics and withdrawal reasons. Paper presented at the 2001 California Association of Institutional Research Annual Conference, Sacramento, $C A$.

Zhao, Y., \& Ho, A. D. (2014). Evaluating the flipped classroom in an undergraduate history course (HarvardX Research Memo).

Ziegelmeier, L.B \& Topaz, C.M (2015). Flipped Calculus: A Study of Student Performance and Perceptions. PRIMUS, 25(9-10). http://dx.doi.org/10.1080/10511970.2015.1031305 


\section{Appendix 1:}

Table 1. The sample questions that were given to students to work in their groups

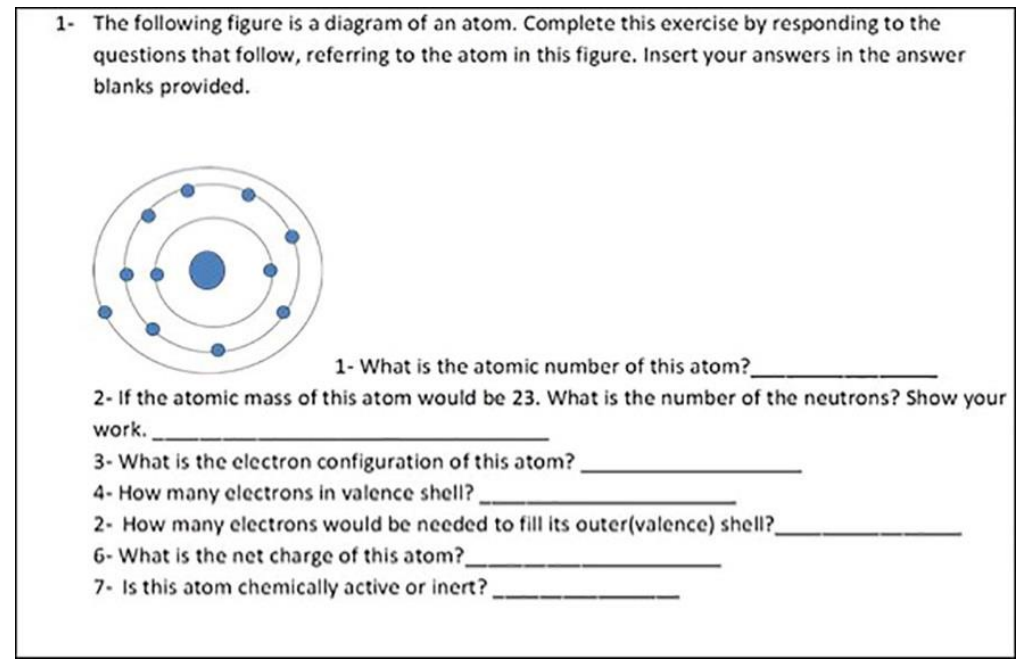

Table 2. Fill in the blank sample questions that focus on definitions and describing the facts

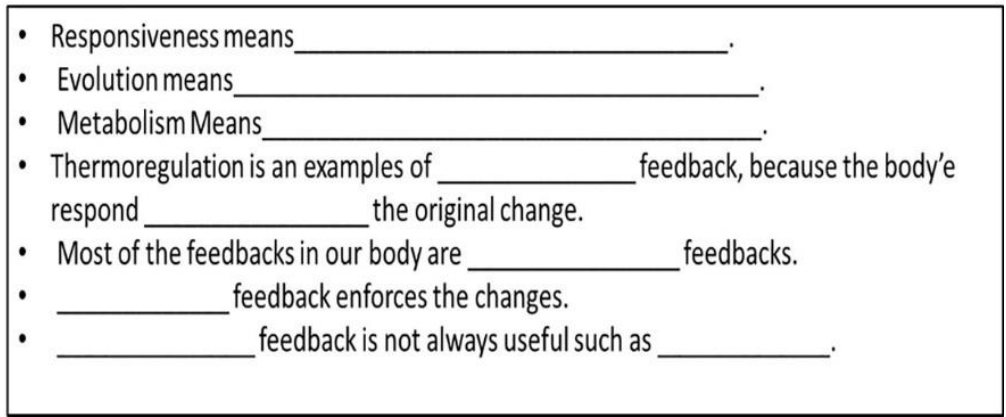

Table 3. The sample of clicker questions

Each of the following graphs show which types of feedback?

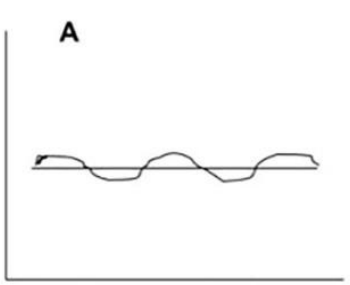

a. A positive, $B$ negative

c. A negative, B positive

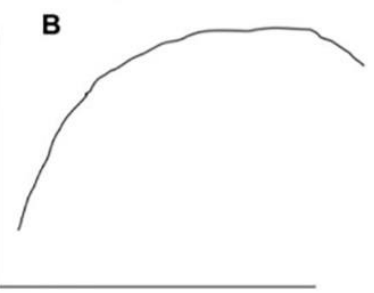

b. A positive, B positive

d. A negative, $B$ negative 